\title{
Observation and Simulation of Available Solar Energy at N'Djamena, Chad
}

\author{
Saka Goni1,2*, Haroun Ali Adannou1,3, Dialo Diop1, Adoum Kriga4, Mahamoud Youssouf Khayal4, \\ Bado Nebon' ${ }^{5}$, Aboubaker Cheidikh Beye ${ }^{1}$, Serigne Abdoul Aziz Niang', Mamadou S. Drame ${ }^{1}$ \\ ${ }^{1}$ Groupe de Laboratoire de Physique des Solides et Sciences des Matériaux, Faculté des Sciences et Techniques, Université Cheikh \\ Anta Diop de Dakar, Dakar, Sénégal \\ ${ }^{2}$ Département de Génie Industriel et Maintenance, Université Polytechnique de Mongo, Mongo, Tchad \\ ${ }^{3}$ Département Génie Chimique, Institut National Supérieur de Pétrole de Mao, Mao, Tchad \\ ${ }^{4}$ Faculté des Sciences Exactes et Appliquées, Université de N’Djamena, N’Djamena, Tchad \\ ${ }^{5}$ Laboratoire d'Energies Thermiques Renouvelables, Université Ouaga I Pr Joseph KI ZERBO de Ouagadougou, Ouagadougou, \\ Burkina Faso \\ Email: *saka_goni@yahoo.fr
}

How to cite this paper: Goni, S., Adannou, H.A., Diop, D., Kriga, A., Khayal, M.Y., Nebon, B., Beye, A.C., Niang, A.S.A. and Drame, M.S. (2019) Observation and Simulation of Available Solar Energy at N'Djamena, Chad. Smart Grid and Renewable Energy, 10, 165-178.

https://doi.org/10.4236/sgre.2019.106011

Received: June 2, 2019

Accepted: June 23, 2019

Published: June 26, 2019

Copyright (C) 2019 by author(s) and Scientific Research Publishing Inc. This work is licensed under the Creative Commons Attribution International License (CC BY 4.0).

http://creativecommons.org/licenses/by/4.0/

\begin{abstract}
The objective of this work is to evaluate the available solar potential at N'Djamena $\left(12^{\circ} 08 \mathrm{~N}, 15^{\circ} 04 \mathrm{E}\right)$ from 2017 to 2018 . To achieve this goal, we used various datasets and model including: the in situ shortwave radiation (by pyranometer) measurement and sunshine duration (by Campbell-Stokes heliograph) obtained from N'Djamena station, observations from MODIS (aerosol optical depth (AOD) and precipitable water) satellite sensors, and simulations from Streamer radiative code. The results show the presence of a good available solar potential with an annual global potential of $4.71 \mathrm{kWh} / \mathrm{m}^{2} / \mathrm{d}$. At the intra-seasonal time scale, there are two maximums for the global solar potential. The first maximum is registered in the month of March (spring) with value of $5.7 \mathrm{kWh} / \mathrm{m}^{2} / \mathrm{d}$ and the second in October (autumn) with value of 5.18 $\mathrm{kWh} / \mathrm{m}^{2} / \mathrm{d}$. However, the minimum of global potential is recorded in winter (from December to February) with values around $3.86 \mathrm{kWh} / \mathrm{m}^{2} / \mathrm{d}$. Then, the measured global irradiation allowed validating the Streamer radiative transfer code with a score of more than $98 \%$. Subsequently, this model was used to simulate direct normal and diffuse irradiation for several types of days (clear, dusty and cloudy days). An examination of the dust influence on solar radiation based on selected cases ( $\mathrm{AOD}=2.05$ ) indicates a mean decrease of 3.33 and 3.17 $\mathrm{kWh} / \mathrm{m}^{2} / \mathrm{d}$, respectively, for the total and direct normal potential. This corresponds to an increase of the diffuse potential of $0.52 \mathrm{kWh} / \mathrm{m}^{2} / \mathrm{d}$. Finally, an increase of $5.82 \mathrm{~cm}$ of precipitable water per day tends to decrease the overall potential of $0.73 \mathrm{kWh} / \mathrm{m}^{2} / \mathrm{d}$ and the direct normal potential of $1.74 \mathrm{kWh} / \mathrm{m}^{2} / \mathrm{d}$. For this cloudy day, the potential has increased more than $0.89 \mathrm{kWh} / \mathrm{m}^{2} / \mathrm{d}$.
\end{abstract}




\section{Keywords}

Solar Potential, Observation, Pyranometer, Streamer, Chad, N'Djamena

\section{Introduction}

Africa is often considered as and referred to the "Sun continent" or the continent where the Sun's influence is the greatest [1]. The theoretical reserves of Africa's solar energy are estimated at 60,000,000 TWh/year, which accounts for almost $40 \%$ of the global total, thus definitely making Africa the most sun-rich continent in the world [2].

The global solar irradiation of Africa is very favorable to the solar energy exploitation. Some parts of the continent are among the sunniest in the world in terms of intensity of solar radiation [3] [4] or duration of insolation [5]. For instance, the center of the eastern Sahara is the driest region of the globe [6]. Likewise, the region between Libya, Egypt, Sudan and Chad, is the sunniest part of the Earth with over 4300 hours per year [7], which is equal to $97 \%$ of the possible total [8]. This region also has the highest mean annual values of solar radiation (the maximum recorded being over $220 \mathrm{kcal} / \mathrm{cm}^{2}$ ) [9]. However, the solar potential is not homogeneous across region and countries in Africa. Indeed, this radiation varies according to the climatic zone (altitude, longitude and latitude) and the atmospheric components (rainfall, aerosol, precipitable water).

The focus of this work is on N'Djamena $\left(12^{\circ} 08 \mathrm{~N}, 15^{\circ} 04 \mathrm{E}\right)$ administrative capital of Chad from 2017 to 2018 . The climate is characterized by warm and dry continental type. From north to south of Chad, we have a succession of Saharan climate in the north, Sahelian in the center and Sudanese in the South [10] [11] [12]. Indeed, Chad is one of the world's sunniest countries which receives more than $3030.91 \pm 176.33$ hours of sunning corresponding to 8.9 hours daily [12]. Similarly, there is a strong gradient between the north and south of the country. For example, daily insolation is $10 \pm 0.41$ hours in the north, $8.85 \pm 1.1$ hours in the center and $7.75 \pm 1.8$ hours in the south [12]. Besides, there is a marked seasonality of the duration of sunshine with maxima in the dry season and minima in the rainy season. The lowest values of sunshine duration are in August (less than 7.5 hours per day). On the contrary, maximums are recorded from November to February with values greater than 9.5 hours per day. The aim of this work is to evaluate the available solar potential (direct normal, diffuse and global) over N'Djamena in Chad. For the first time a pyranometer has been used to characterize the global potential and Streamer model which serves to estimate the direct normal and diffuse potential. The paper is organized as follows. "Data and Methodology" presents the study area (N'Djamena station), in situ measurement (by pyranometer and heliograph), the space (MODIS sensor) data (aerosol optical depth (AOD) and precipitable water) and Streamer radiative transfer code. The results are presented in "Results and discussions". 


\section{Data and Methodology}

\subsection{Presentation of N'Djamena Site}

The focus of this work is on the N'Djamena city $\left(12^{\circ} 08 \mathrm{~N}, 15^{\circ} 04 \mathrm{E}\right)$ administrative capital of Chad Republic in Central Africa. In addition to the Campbell-Stokes heliograph (which measured sunstroke), this site has recently had a pyranometer (vantage Pro2 weather station) measuring the global solar irradiation. Climatic conditions over N'Djamena site are like the Sahel region (West African region located between $8^{\circ} \mathrm{N}-18^{\circ} \mathrm{N}$ and $20^{\circ} \mathrm{W}-20^{\circ} \mathrm{E}$ ) with 7 months of the dry season (from November to May) and 5 months of the rainy season (from June to October). This new instrumented site is a unique opportunity to study the links between meteorological and climatic parameters (insolation, aerosols, clouds, etc.) and solar radiation over this region.

\subsection{Presentation of Instruments and Data}

Several data are used in this study of solar potential in N'Djamena from 2017 to 2018. First, solar irradiation measurements are taken by pyranometer (vantage Pro2 weather station) installed at the National Research and Development Center in N'Djamena in 2017. This is the first time that such types of in situ measurements have been carried out in Chad. Likewise, daily insolation measurements (at sunrise and at sunset) are carried out using a Campbell-Stokes heliograph come from this center. And finally, the atmospheric data (aerosol optical depth at $550 \mathrm{~nm}$ and precipitable water) which serve as input to Streamer model and intercomparison tools are derived from the MODIS sensor from space. MODIS is a sensor transported by the TERRA satellites since December 1999 and Aqua in April 2002. TERRA sweeps the earth surface from the North to the South around the equator in the morning around 10:30 am while Aqua occurs in the evening, around 10:30 am in an orbit oriented South-North of the Equator [13]. MODIS has 36 spectral bands that enable it to provide measurements on the atmosphere, the Earth and the ocean, 7 of which are used to study aerosols (466, 553, 644, 855, 1243, 1632 and $2119 \mathrm{~nm}$ ). In addition, it uses different algorithms to invert aerosol properties on Earth [14] and on seas [15] where measurements are made with a spatial resolution ranging from 1 to 250 $\mathrm{km}$ and temporal from 1 to 2 days. For our study, MODIS-Terra and MODIS-Aqua Deep-Blue inversions at $550 \mathrm{~nm}$ (available on NASA's Giovanni site (https://giovanni.gsfc.nasa.gov/giovanni/) are used indeed, the Deep Blue algorithm takes into account cloud masks, the aerosol model and the reflection of shiny surfaces [13] [16]. This makes it possible to eliminate contaminations due to the reflection of the shiny surfaces and improve the qualified observations in level 2 in areas like the desert of the Sahara, the arid, semi-arid and urban regions where reflectivity is very significant [17].

\subsection{The Streamer Code for Radiative Transfer}

The streamer code developed by [18] and [19] is a simple and fast model for as- 
sessing the radiative impact of atmospheric aerosols. In this model, the terms of the radiative budget are treated separately at different spectral bands. This is incident solar radiation calculated at wavelengths ranging from 0.4 to 0.8 microns contained in the visible spectrum and telluric infrared radiation between 0.8 and 500 microns. Indeed, the Streamer code calculates luminances and flows by cutting the atmosphere in several layers in all directions. These quantities are calculated on narrow bands and on the entire solar spectrum, then for 25-atmosphere levels distributed between the surface and the top of the atmosphere. This code uses six (06) predefined aerosol models under the terms tropospheric, marine, rural, arctic haze, smoke and urban aerosol to simulate radiation on the surface. These models were created using a Mie code that enables to generate the optical parameters of the particle. Thus, each aerosol model predefined in the Streamer code contains the extinction, absorption and asymmetry coefficients of the particle considered throughout the solar spectrum. Moreover, the absorption of the main gases $\left(\mathrm{H}_{2} \mathrm{O}, \mathrm{O}_{3}, \mathrm{CO}_{2}, \mathrm{O}_{2}\right)$ in the visible spectrum is included but, it can be omitted in calculations. The surface can be considered as a Lambertian one with or without isotropic reflection through its bidirectional reflectance distribution function [20]. For our study, the rural model is used considering the nature of dominating particles in the Sahel, especially in Chad. Moreover, for the simulation of surface level solar flows, the model must be thoroughly and accurately completed [21].

In this study, the Streamer code inputs data for surfaces fluxes estimation for each day are: the aerosol optical depth, the precipitable water, the aerosol model, the surface albedo, the ozone, and the site geographic coordinates.

\subsection{Global Solar Potential on the Horizontal Plane}

Sizing of photovoltaic systems requires precise knowledge of available solar potential on a plane, usually on the horizontal plane.

From the global radiation $(G)$ measured, the available solar potential $\left(E_{g}\right)$ is calculated using the following equation:

$$
E_{g}=\int_{(L s)}^{(C s)} G(t) * \mathrm{~d} t
$$

$L s$, time of sunrise (h); Cs, time of sunset (h).

\subsection{Selection of Dates}

In order to assess and simulate the solar potential (global, diffuse and direct normal) in N'Djamena, a classification was performed based on three types of days organized as follow: 1) clear days (a day without aerosol), 2) dusty days (maximum of aerosol) and 3) cloudy days (maximum of clouds). This classification is based on aerosol optical depth and water precipitable provided by MODIS sensors. Similarly to the previous study by [22], the upper threshold of aerosol optical depth is fixed to 0.1 per day. Table 1 shows the daily averaged total AOD (at $550 \mathrm{~nm}$ ), precipitable water (WP) and global solar potential $(\mathrm{H})$ 
for a total of 6 selected days (2 days per day type) for N'Djamena station.

\section{Results and Discussion}

\subsection{Seasonal Variability of Global Potential at N'Djamena}

Figure 1 represents the monthly average of global solar irradiation on the horizontal plane from 2017 to 2018 in N'Djamena.

First, there is a significant seasonal variability of the global solar potential in N'Djamena. The maxima are observed during the dry season, i.e., in the spring (from March to May) with values around $5.42 \mathrm{kWh} / \mathrm{m}^{2} / \mathrm{d}$ and in autumn (from September to November) with values of $4.97 \mathrm{kWh} / \mathrm{m}^{2} / \mathrm{d}$, certainly linked to an intense solar activity. Then, the minima are observed in the winter from December to February (probably due to the sun height) and in summer from June to August,

Table 1. Daily averaged for MODIS and pyranometer observations for each selected days (clear, clean, dusty, or cloudy) in N'Djamena. The parameters are total aerosol optical depth (AOD), precipitable water (WP) and global solar potential (H).

\begin{tabular}{ccccccccc}
\hline Date & $\begin{array}{c}\text { Temperature } \\
\left({ }^{\circ} \mathrm{C}\right)\end{array}$ & Albedo & Emissivity & Ozone & $\begin{array}{c}\text { WP } \\
(\mathrm{cm})\end{array}$ & AOD & $\begin{array}{c}\mathrm{H} \\
\left(\mathrm{kW} / \mathrm{m}^{2} / \mathrm{d}\right)\end{array}$ & day \\
\hline $10 / 19 / 2018$ & 29.5 & 0.232 & 0.954 & 248.019 & 2.17 & 0.017 & 5.59 & Clear \\
$12 / 27 / 2018$ & 28 & 0.232 & 0.954 & 248.019 & 1.97 & 0.018 & 3.8 & Clear \\
$03 / 29 / 2018$ & 31.5 & 0.232 & 0.954 & 248.019 & 2.75 & 2.87 & 2.18 & dusty \\
$04 / 01 / 2018$ & 30.86 & 0.232 & 0.954 & 248.019 & 3.75 & 2.05 & 3.58 & dusty \\
$08 / 23 / 2018$ & 28 & 0.232 & 0.954 & 248.019 & 5.82 & 0.03 & 4.14 & Cloudy \\
$08 / 24 / 2018$ & 27.5 & 0.232 & 0.954 & 248.019 & 5.7 & 0.15 & 5.82 & Cloudy \\
\hline
\end{tabular}

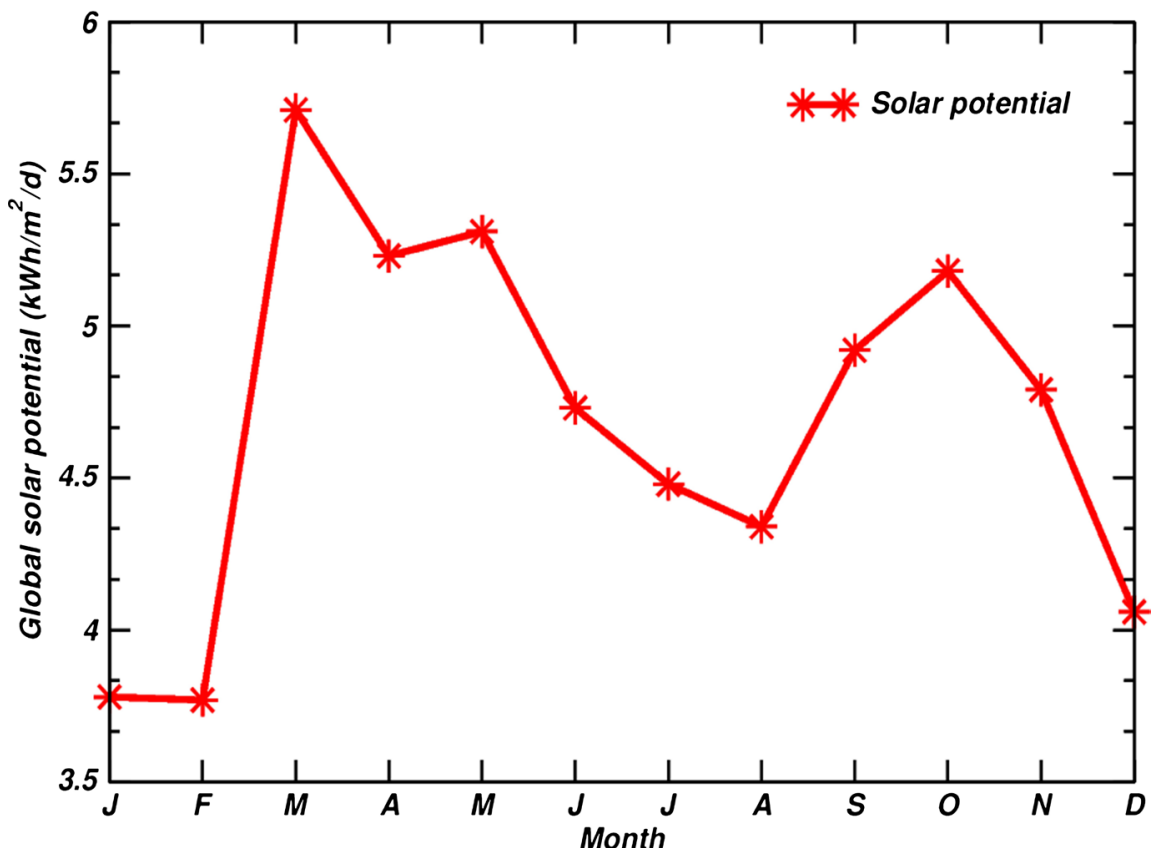

Figure 1. Monthly average of available global solar potential $\left(\mathrm{kWh} / \mathrm{m}^{2} / \mathrm{d}\right)$ at $\mathrm{N}^{\prime} \mathrm{Djamena}$ from 2017 to 2018. 
due to the cloud cover. The winter minimums correspond to a monthly average of solar irradiation varying between $3.87 \mathrm{kWh} / \mathrm{m}^{2} / \mathrm{d}$ and that in summer (rainy season) around $4.60 \mathrm{kWh} / \mathrm{m}^{2} / \mathrm{d}$. In summary, the most favorable month in term of global solar potential are Mars in spring with values around $6 \mathrm{kWh} / \mathrm{m}^{2} / \mathrm{d}$ and the least favorable month is January with a value of $3.87 \mathrm{kWh} / \mathrm{m}^{2} / \mathrm{d}$. Overall, the annual amount of available solar potential is of $4.71 \mathrm{kWh} / \mathrm{m}^{2} / \mathrm{d} /$ day for the global energy on a horizontal plane in N'Djamena from 2017 to 2018. Seasonal fluctuations of global solar potential in N'Djamena are probably due to the diffusion and absorption properties of atmospheric elements such as aerosols, clouds, gases and water vapor and also by the sun activity (insolation and the height of the sun).

\subsection{Seasonal Effects of AOD, Precipitable Water and Insolation on Global Solar Potential}

To evaluate the impact of the atmospheric parameters and the insolation on the monthly potential solar, we are performed qualitative comparisons. Figure 2 shows the seasonal evolution of the global solar potential in comparison with insolation (Figure 2(a)), aerosol AOD (Figure 2(b)) and precipitable water (Figure 2(c)) from 2017 to 2018 in N'Djamena.
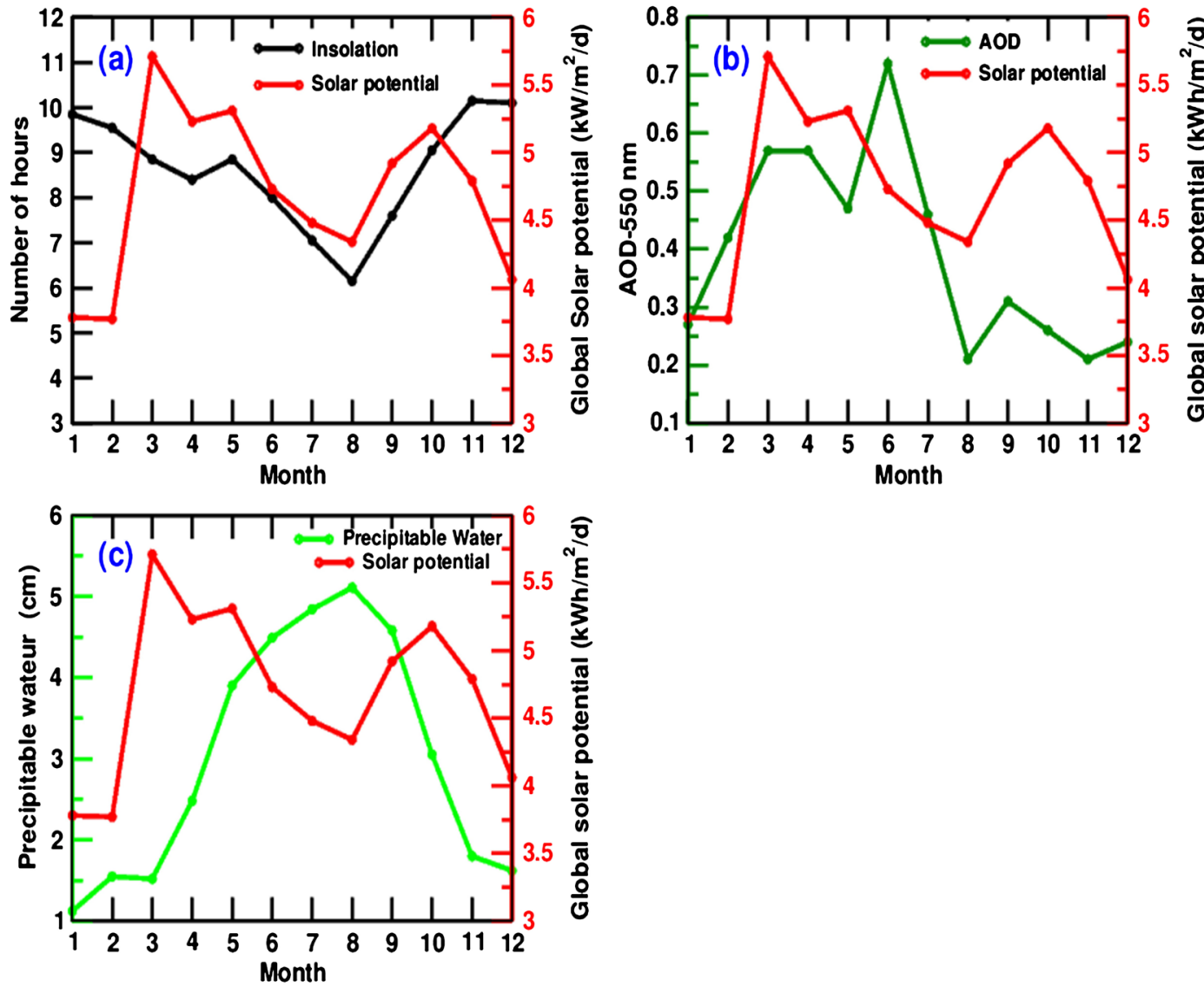

Figure 2. Qualitative effects of insolation (a), aerosol AOD (b) and Precipitable Water (d) on global solar potential at N’Djamena from 2017 to 2018. 
Overall, we note that insolation duration (Figure 2(a)) follows the same trends that the solar potential except in winter (December to February). Indeed, the increasing trends are visible in these two curves from March to August. Furthermore, we note a decreasing trend of these two parameters from August to November. During the rainy season (especially in August), the insolation and the global solar radiation are minimums which provide cloud cover. The minimum of solar potential and sunstroke recorded during the rainy season (especially in august) is mainly due to cloud cover. However, insolation peaks recorded in winter (from November to February) are not correlated with solar potential. During this season, we note the lowest values of the solar potential whereas these are the longest days in terms of sunshine.

Figure 2(b) illustrates the seasonal evolution of solar potential measured and aerosol optical depth (AOD) from MODIS sensor at $550 \mathrm{~nm}$ in N'Djamena. This figure shows that AOD is mostly correlated to solar potential during autumn from August to December. Indeed, the minimums in AOD correspond to an increase in radiation during this season. However for other seasons, we note that the main parameters influencing surface irradiation are other than aerosols.

Figure 2(c) illustrates the seasonal evolution of solar potential measured and precipitable water from the MODIS sensor at in N'Djamena. We observe that this parameter is strongly correlated with the solar potential except in winter (December to February) in N'Djamena. The presence of clouds in the atmosphere tends to significantly decrease radiation, especially in August.

In summary, it can be said that insolation, aerosols and clouds are parameters that influence the incident solar radiation. The combination of the effects of these three parameters makes it possible to better evaluate the solar potential from February to November. However, the lowest values of solar potential recorded in winter (from December to February) may be due to the height of the sun.

\subsection{Diurnal Validation of Streamer Code in N'Djamena}

The pyranometer installed in N'Djamena measures only the global radiation. Thus, to obtain the different components (diffuse and direct normal fluxes), we use the Streamer radiative transfer model. For that, we compare measurement and simulation for our three types of days (clear, dusty and cloudy). For each type of day (clear, cloudy and dusty), two days were chosen in 2018 and the corresponding fluxes (diffuse and normal direct) were stimulated by Streamer. We begin by validating the model by existing in situ measurements (solar global irradiation) in N'Djamena.

We represent in Figure 3(a) and Figure 3(c), the diurnal cycle of simulated (red) and observed (black) global solar radiation for the two clear days (no aerosol) in 2018. For clear sky cases, the selected days are October 19 (with an AOD of 0.017 , wp of $2.17 \mathrm{~cm}$ for a global potential of $5.59 \mathrm{kWh} / \mathrm{m}^{2} / \mathrm{d}$ ) and December 27 (with an AOD of 0.0187, wp of $1.97 \mathrm{~cm}$ for a global potential of 3.8 $\mathrm{kWh} / \mathrm{m}^{2} / \mathrm{d}$ ). We note that, Streamer model perfectly simulates the observation in 

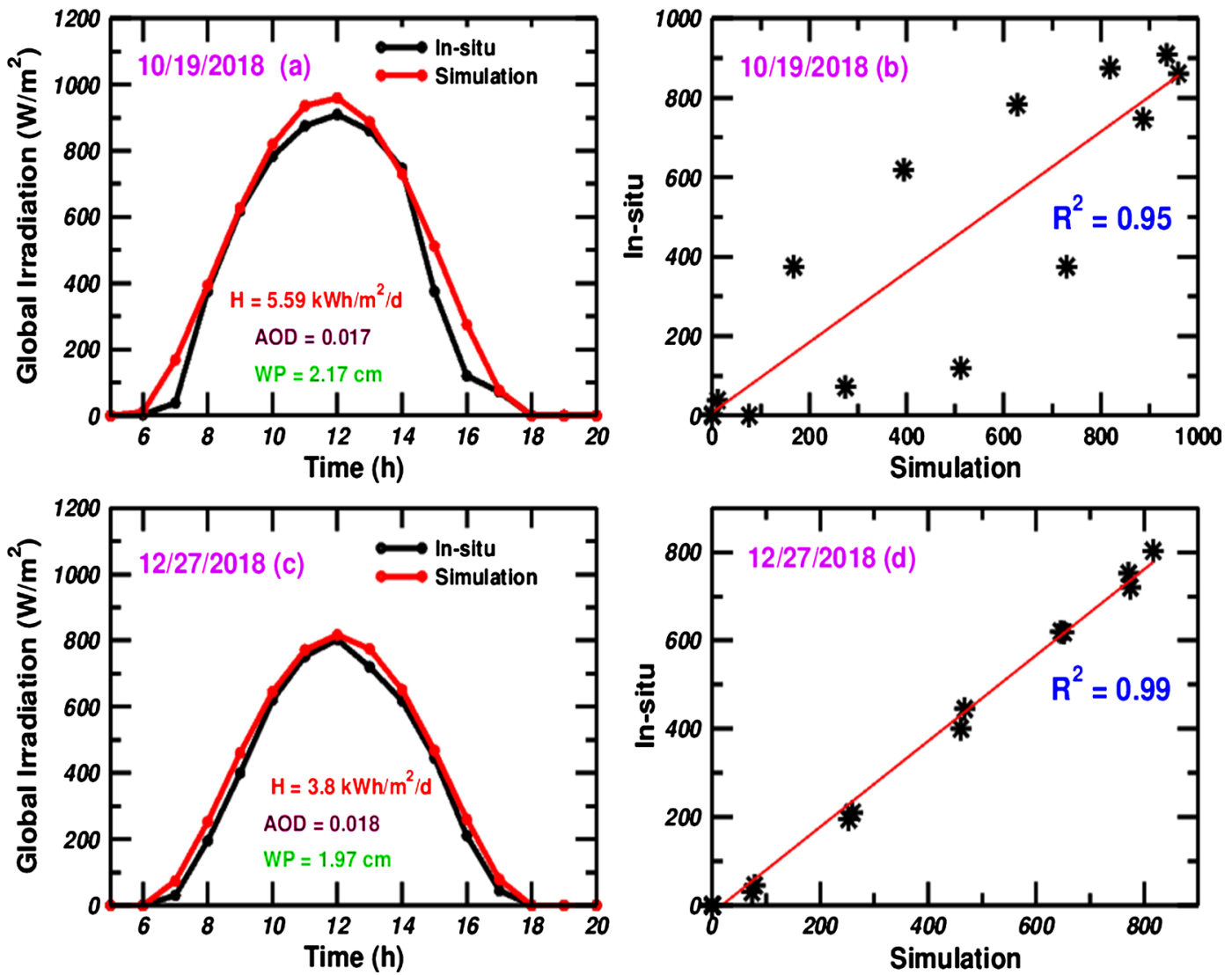

Figure 3. Diurnal cycle of simulated (red) and observed (black) global solar radiation for the two clear (no aerosol) days in October 19 (a) and December 27, 2018 (c) in N’Djamena. The linear regression lines between measurement and simulation are shown in (b) and (d) respectively for October 19 and for December 27.

N'Djamena for these days without aerosols. The correlations rates of more than 98\% (Figure 3(b) and Figure 3(d)) confirm the reliability of this model for these types of days.

Then, the comparisons for dusty days are made in Figures 4(a)-(d). For dusty sky cases. The selected days are March 29 (with an AOD of 2.87, wp of $2.75 \mathrm{~cm}$ and a global potential of $2.18 \mathrm{kWh} / \mathrm{m}^{2} / \mathrm{d}$ ) and April 01 (with an AOD of 2.05, wp of $3.75 \mathrm{~cm}$ and a global potential of $3.58 \mathrm{kWh} / \mathrm{m}^{2} / \mathrm{d}$ ). Here the relevant parameter is aerosol optical depth (AOD). Even in the case of dust events, the streamer model simulates observation very well with scores of over $98 \%$.

And finally, the same comparisons are made for cloudy days in Figures 5(a)-(d). For cloudy sky cases, the selected days are August 23 (with an AOD of 0.03 , wp of $5.82 \mathrm{~cm}$ and a global potential of $4.14 \mathrm{kWh} / \mathrm{m}^{2} / \mathrm{d}$ ) and August 24 (with an AOD of 0.15, wp of $5.70 \mathrm{~cm}$ a global potential of $5.82 \mathrm{kWh} / \mathrm{m}^{2} / \mathrm{d}$ ). Here the relevant parameter is precipitable water (WP). As for clear days the model simulates very well the observation with scores of $98 \%$. However, the model is struggling to represent rapid cloud passages such as that between 12 and $1 \mathrm{pm}$ on August 23, 2018.

In summary we can say that this model is validated by the observations with 

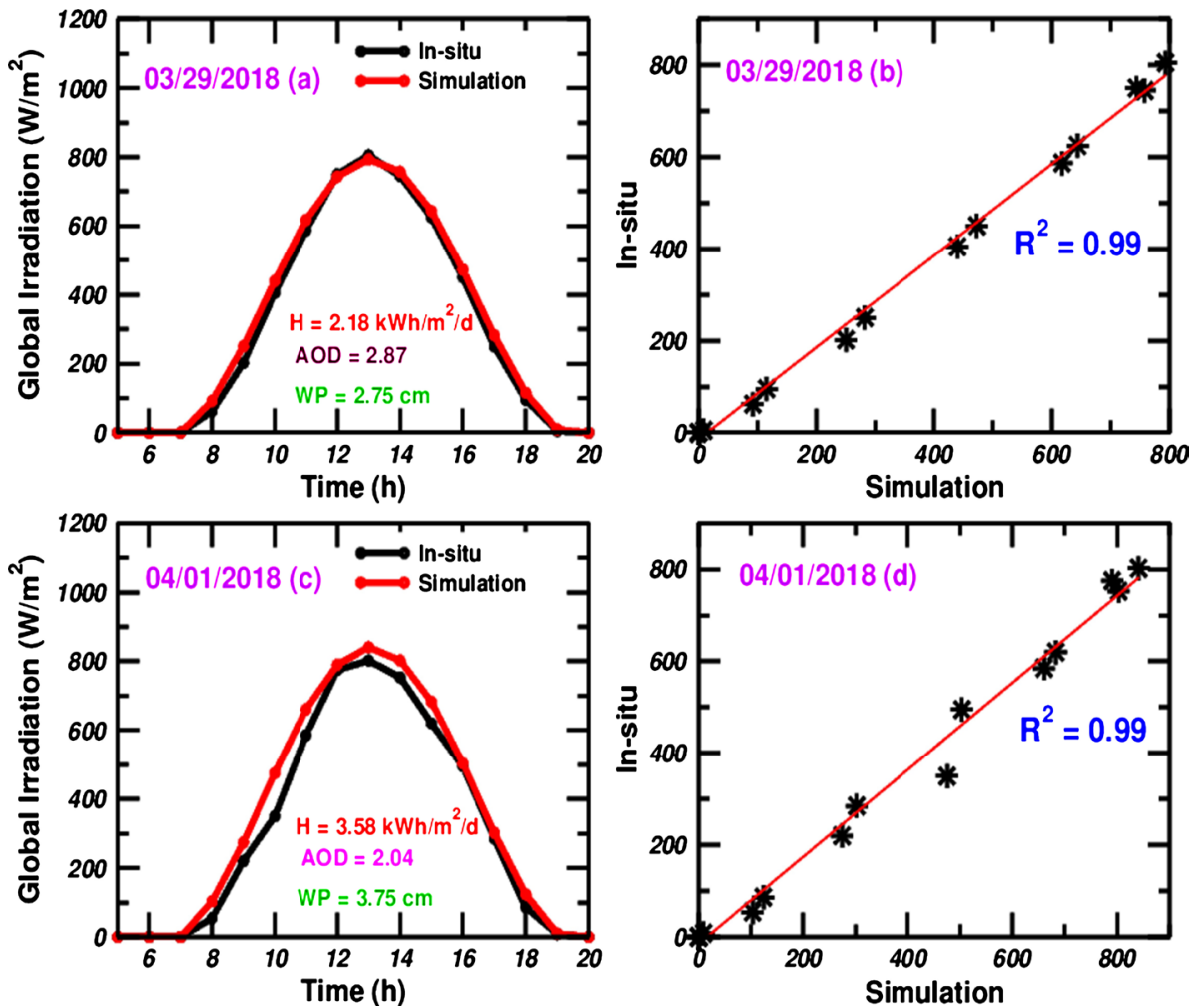

Figure 4. Diurnal cycle of simulated (red) and observed (black) global solar radiation for the two dusty (maximum of AOD) days in March 29 (a) and April 01, 2018 (c) in N'Djamena. The linear regression lines between measurement and simulation are shown in (b) and (d) respectively for March 29 and for April 01.
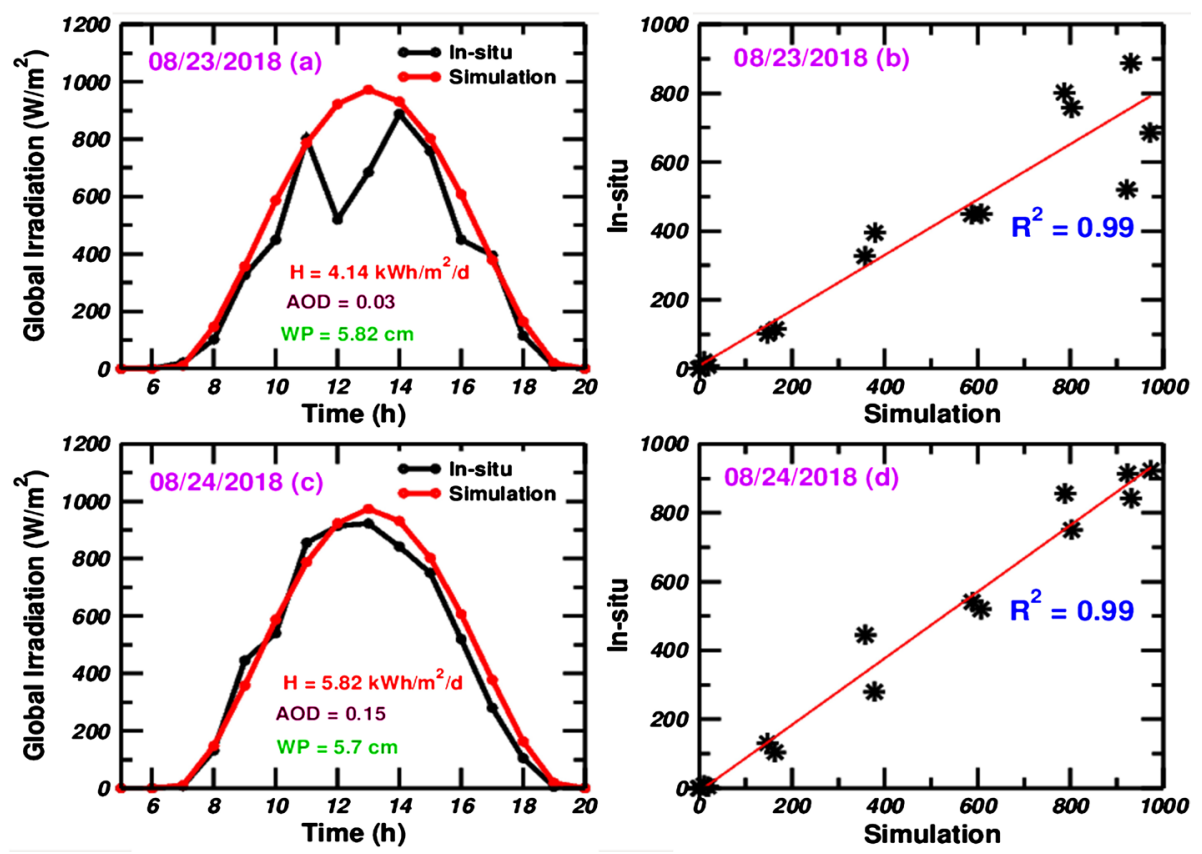

Figure 5. Diurnal cycle of simulated (red) and observed (black) global solar radiation for the two cloudy (maximum of precipitable water) days in August 23 (a) and August 24, 2018 (c) in N'Djamena. The linear regression lines between measurement and simulation are shown in (b) and (d) respectively for August 23 and for August 24. 
correlation coefficients of more than $98 \%$ for the global potential. Then we will be able to trust this model to simulate the direct normal and diffuse potential for which we do not have observations.

\subsection{Simulation of Direct and Diffuse Radiation for a Few Days}

In this part we use the streamer model to simulate the diffuse and direct normal irradiation. For this, only dusty and cloudy days are used to evaluate the impact of aerosols and clouds on these radiations. For each day, two simulations were performed: a first simulation (with aerosol or with cloud) and a second (without aerosol or without cloud).

Figure 6 shows the diffuse (left) and direct normal (right) solar potential simulations for the two dusty days respectively on October 29 (a and c) and April 1 (b and d). For each this day, two simulations are carried out: one without aerosol (i.e., $\mathrm{AOD}=0$ ) and another with the daily AOD measured by the MODIS sensor above N'Djamena. This figure shows that the increase of aerosol AOD causes a decreasesof direct (c) normal irradiation and increase of diffuse irradiation (a).

Table 2 summarizes the impact of the presence of aerosol (AOD) on diffuse potential, direct normal and global for April 1, 2018, in N'Djamena. Overall, if AOD goes from 0 to 2.05 , the global solar potential decreases by $3.33 \mathrm{kWh} / \mathrm{m}^{2} / \mathrm{d}$, the diffuse increases by $0.52 \mathrm{kWh} / \mathrm{m}^{2} / \mathrm{d}$, and the normal direct increases by 3.17 $\mathrm{kWh} / \mathrm{m}^{2} / \mathrm{d}$. These aerosols are generally composed of dust that tends to backscatter radiation to space.

\section{Dusty days}
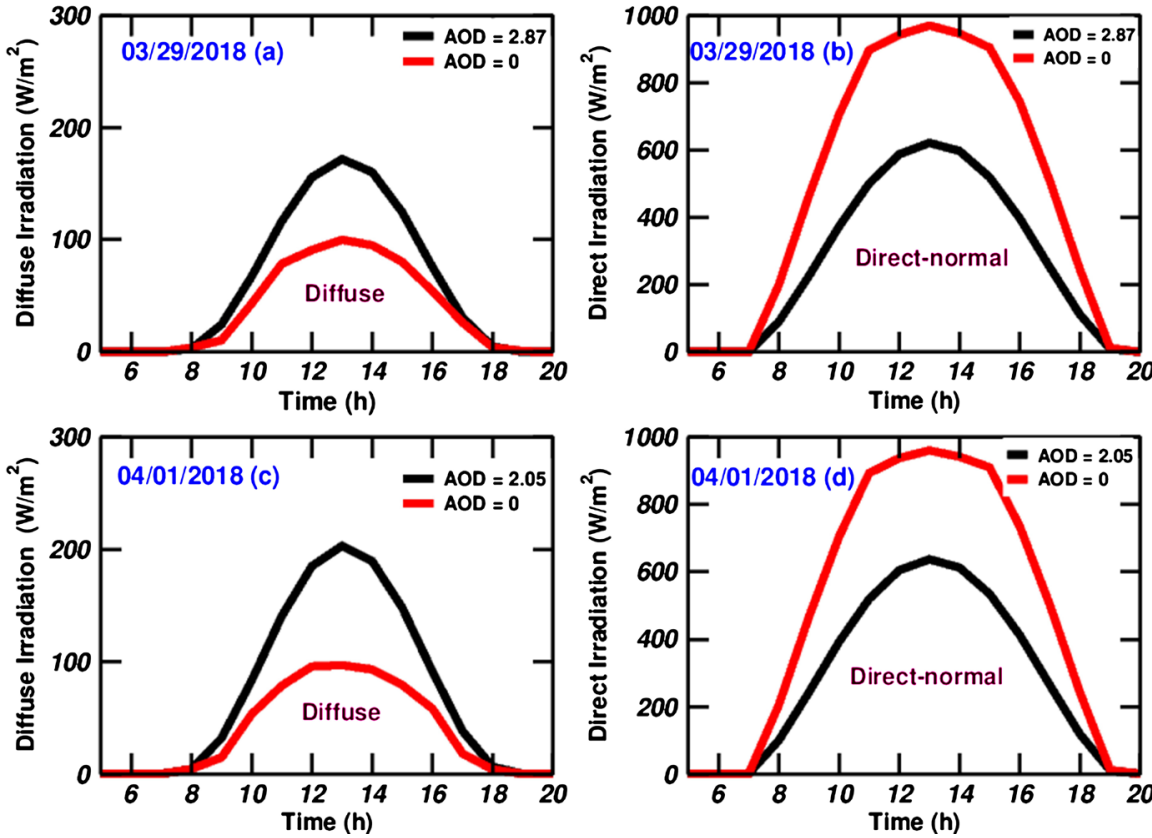

Figure 6. Simulation of the diurnal cycle of diffuse (left) and direct (right) fluxes with the streamer code by varying the value of the AOD for march $29(\mathrm{AOD}=0$ and $\mathrm{AOD}=2.87)$ and April $1(\mathrm{AOD}=0$ and $\mathrm{AOD}=2.05)$. 
Figure 7 shows the diffuse (left) and direct normal (right) solar potential simulations for the two cloudy days respectively on August 23 (a and c) and August 24 (b and d). For this day, two simulations are carried out: one without cloud (i.e., precipitable water $=0$ ) and another with the daily precipitable water measured by the MODIS sensor above N'Djamena. This figure shows that the increase of precipitable water causes a decrease of direct (c) normal irradiation and an increase of diffuse irradiation (a).

Table 3 summarizes the impact of clouds on diffuse potential, direct normal and global for August 23, 2018, in N'Djamena. Overall, if precipitable water goes from 0 to $5.82 \mathrm{~cm}$, the global solar potential decreases by $0.73 \mathrm{kWh} / \mathrm{m}^{2} / \mathrm{d}$, the diffuse increases by $0.89 \mathrm{kWh} / \mathrm{m}^{2} / \mathrm{d}$, and the normal direct increases by 1.74 $\mathrm{kWh} / \mathrm{m}^{2} / \mathrm{d}$. These aerosols are generally composed of dust that tends to backscatter radiation to space. These convective clouds (present during the rainy season) reflect the incident radiation toward space, thus reducing the available

Table 2. Dust daily effect on available solar potential (direct, diffuse and global) on April 1,2018 in N'Djamena.

\begin{tabular}{cccc}
\hline Date & $\begin{array}{c}\text { Direct potential } \\
\left(\mathrm{kWh} / \mathrm{m}^{2} / \mathrm{d}\right)\end{array}$ & $\begin{array}{c}\text { Diffuse potential } \\
\left(\mathrm{kWh} / \mathrm{m}^{2} / \mathrm{d}\right)\end{array}$ & $\begin{array}{c}\text { Global potential } \\
\left(\mathrm{kWh} / \mathrm{m}^{2} / \mathrm{d}\right)\end{array}$ \\
\hline $2018 / 04 / 01(\mathrm{AOD}=0)$ & 7.78 & 0.60 & 8.47 \\
$2018 / 04 / 01(\mathrm{AOD}=2.5)$ & 4.45 & 1.12 & 5.57 \\
Difference & 3.33 & -0.52 & 3.17 \\
\hline
\end{tabular}

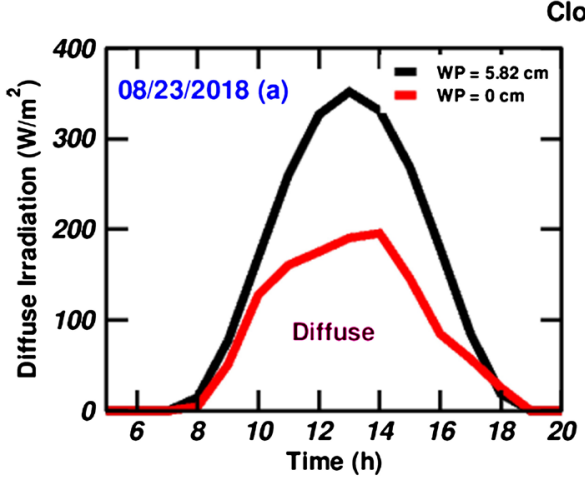

Cloudy days
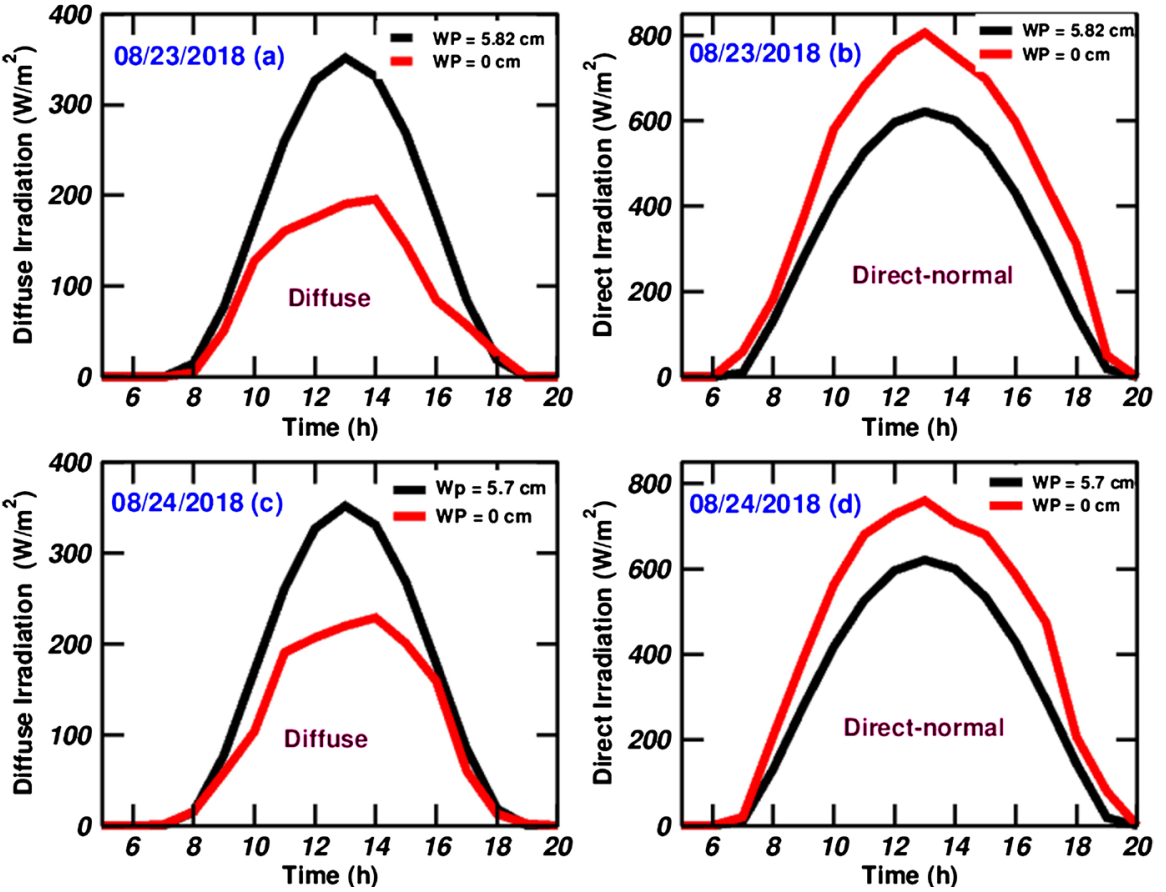

Figure 7. Simulation of the diurnal cycle of diffuse (left) and direct (right) fluxes with the streamer code by varying the value of the water vapor for August 23 ( $w p=0 \mathrm{~cm}$ and $\mathrm{wp}=$ $5.82 \mathrm{~cm})$ and August $24(\mathrm{wp}=0 \mathrm{~cm}$ and $\mathrm{wp}=5.7 \mathrm{~cm})$. 
Table 3. Clouds daily effect on available solar potential (direct, diffuse and global) on August 23, 2018 in N'Djamena.

\begin{tabular}{cccc}
\hline Date & $\begin{array}{c}\text { Direct potential } \\
\left(\mathrm{kWh} / \mathrm{m}^{2} / \mathrm{d}\right)\end{array}$ & $\begin{array}{c}\text { Diffuse potential } \\
\left(\mathrm{kWh} / \mathrm{m}^{2} / \mathrm{d}\right)\end{array}$ & $\begin{array}{c}\text { Global potential } \\
\left(\mathrm{kWh} / \mathrm{m}^{2} / \mathrm{d}\right)\end{array}$ \\
\hline $2018 / 08 / 23(\mathrm{wp}=0 \mathrm{~cm})$ & 6.35 & 1.19 & 7.42 \\
$2018 / 08 / 23(\mathrm{wp}=5.82 \mathrm{~cm})$ & 4.61 & 2.08 & 6.69 \\
Difference & 1.74 & -0.89 & 0.73 \\
\hline
\end{tabular}

solar energy on the surface of the Earth.

\section{Conclusion}

This study involved evaluating the available solar potential by observations and simulations in N'Djamena, Chad. The observations have allowed evaluating the global potential with an annual average of $4.71 \mathrm{kWh} / \mathrm{m}^{2} / \mathrm{d}$. The most favorable season (in terms of global potential) is from March and November. However, winter (from December to February) is characterized by a minimum of 3.86 $\mathrm{kWh} / \mathrm{m}^{2} / \mathrm{d}$ of global solar potential. Then, the Streamer radiative transfer code was validated by the global measurements in N'Djamena with a score of more than $98 \%$. Afterwards, Streamer code was used to simulate the direct normal and diffuse irradiation for several types of days. An examination of the dust (or clouds) influence on solar radiation based on selected cases indicates a significant decrease in direct normal and global solar potential in the presence of dust or cloud. For instance, for the day of April 1, 2018, the presence of dust (AOD = 2.05) resulted in a decrease of 3.33 and $3.17 \mathrm{kWh} / \mathrm{m}^{2} / \mathrm{d}$, respectively, for the global and direct normal potential. This dust also causes an increase of the diffuse potential of $0.52 \mathrm{kWh} / \mathrm{m}^{2} / \mathrm{d}$.

\section{Acknowledgements}

By this article, I would like to thank the service of the direction of the General of the meteorological national to provide me these data and also Mrs. Felicité of the CNRD. I wish to acknowledge the excellent encouragement, techniques, advice and recommendations provided by Mrs. Sy (SOUKEYNA) for her contribution to the editorial audit in English.

\section{Conflicts of Interest}

The authors declare no conflicts of interest regarding the publication of this paper.

\section{References}

[1] Griffiths, I.L. (2013) The Atlas of African Affairs. Taylor \& Francis, London, 15. https://doi.org/10.4324/9780203713785

[2] Liu, Z.-Y. (2015) Global Energy Interconnection. Elsevier Science, 30.

[3] Riordan, P. and Bourget, P.G. (1997) U.S. Army Engineer Topographic Laborato- 
ries, World Weather Extremes, The Laboratories, 66.

[4] Climate and Life. Elsevier Science, 151.

[5] https://books.google.fr/books?hl=fr\&id=n_GoHp1wS3cC\&dq=eastern+Sahara+brig $\mathrm{ht}+$ sunshine \&focus $=$ searchwithinvolume \&q=sahara

[6] https://books.google.fr/books?id=_Rvs7NkfeLEC\&pg=PA16\&dq=eastern + Sahara + h igh+air+moisture + occur\&hl=fr\&sa=X\&ved=0ahUKEwjys52QrMLgAhXv2OAKHb SQCRAQ6AEIKDAA\#v=onepage\&q=eastern\%20Sahara\%20high\%20air\%20moistu re\%20occur\&f=false

[7] Dunlop, S. A Dictionary of Weather. OUP, Oxford.

[8] https://books.google.fr/books?hl=fr\&id=n_GoHp1wS3cC\&dq=eastern+Sahara+brig $\underline{\mathrm{ht}+\text { sunshine\&focus }=\text { searchwithinvolume } \& \mathrm{q}=430}$

[9] Wadsworth, F.H. (1997) Forest Production for Tropical America. U.S. Department of Agriculture, Agricultural Handbook.

[10] Bedoum, A., BoukaBiona, C., Alladoum, B., Issak, A. and Laohoté, B. (2013) Variabilités climatiques et ruptures dans les séries des précipitations en République du Tchad. Revue Ivoirienne des Sciences et Technologie, 21-22, 187-208.

[11] Maharana, P., Abdel-Lathif, A.Y. and Pattnayak, K.C. (2018) Observed Climate Variability over Chad Using Multiple Observational and Reanalysis Datasets. Global and Planetary Change, 162, 252-265. https://doi.org/10.1016/j.gloplacha.2018.01.013

[12] Goni, S., Adannou, H.A., Diop, D., Drame, M.S., Tikri, B., Barka, M. and Beye, A.C. (2019) Long-Term Variation of Sunshine Duration and Their Inter-Action with Meteorogical Parameters over Chad, Central Africa. Natural Resources, 10, 47-58. https://doi.org/10.4236/nr.2019.103004

[13] Levy, R.C., Remer, L.A., Mattoo, S., Vermote, E.F. and Kaufman, Y.J. (2007) Second-Generation Operational Algorithm: Retrieval of Aerosol Properties over Land from Inversion of Moderate Resolution Imaging Spectroradiometer Spectral Reflectance. Journal of Geophysical Research: Atmospheres, 112, D13211. https://doi.org/10.1029/2006JD007811

[14] Kaufman, Y.J.D., Tanr, L., Remer, A., Vermote, E.F. and Chu, A. (1997) Operational Remote Sensing of Tropospheric Aerosol over Land from EOS Moderate Resolution Imaging Spectroradiometer. Journal of Geophysical Research: Atmospheres, 102, 17051-17067. https://doi.org/10.1029/96JD03988

[15] Tanré, D., Kaufman, Y.J., Herman, M. and Mattoo, S. (1997) Remote Sensing of Aerosol Properties over Oceans Using the MODIS/EOS Spectral Radiances. Journal of Geophysical Research: Atmospheres, 102, 16971-16988.

[16] Remer, L.A., Kaufman, Y.J., Tanré, D., Mattoo, S., Chu, D.A., Martins, J.V., Li, R.R., Ichoku, C., Levy, R.C., Kleidman, R.G., Eck, T.F., Vermote, E. and Holben, B.N. (2005) The MODIS Aerosol Algorithm, Products, and Validation. American Meteorological Society, 62, 947-973. https://doi.org/10.1175/JAS3385.1

[17] Hsu, N.C., Tsay, S., King, M.D., Member, S. and Herman, J.R. (2004) Aerosol Properties over Bright-Reflecting Source Regions. IEEE Transactions on Geoscience and Remote Sensing, 42, 557-569. https://doi.org/10.1109/TGRS.2004.824067

[18] Key, J.R. and Schweiger, A.J. (1998) Tools for Atmospheric Radiative Transfer: Streamer and FluxNet. Computers \& Geosciences, 24, 443-451. https://doi.org/10.1016/S0098-3004(97)00130-1

[19] Key, J. (2001) Streamer User's Guide. Cooperative Institute for Meteorological Satellite Studies, University of Wisconsin, $96 \mathrm{p}$. 
[20] Drame, M.S., Camara, M. and Gaye, A.T. (2012) Simulation de l'impact des aérosols sur le rayonnement solaire à Mbour, Sénégal. La Météorologie, 79, 51-57. https://doi.org/10.4267/2042/48513

[21] Camille, V. (2007) Etude de l'impact radiatif des aérosols dans la couche limite planetaire. Université de Versailles.

[22] Drame, M., Bilal, B.O., Camara, M., Sambou, V. and Gaye, A. (2012) Impacts of Aerosols on Available Solar Energy at Mbour, Senegal. Journal of Renewable Sustainable Energy, 4, Article ID: 013105. https://doi.org/10.1063/1.3682078 